\title{
A REALIZAÇÃO DO TESTE ANTI-HIV NO PRÉ-NATAL: OS SIGNIFICADOS PARA A GESTANTE
}

\author{
The establishment of ANTI-HIV test in pre-natal: meanings \\ for pregnancy \\ El establecimiento de la lucha contra la prueba del vih en \\ pre-navidad: significados para el embarazo
}

Roberta Maria de Oliveira Silva ${ }^{1}$

Carla Luzia França Araújo ${ }^{2}$

Fatima Maria Trigo da Paz ${ }^{3}$

\section{RESUMO}

0 estudo teve por objetivo conhecer e analisar o significado da realização do teste anti-HIV no pré-natal para as gestantes. Tratase de uma pesquisa com abordagem qualitativa e foi realizada em um Hospital Escola e em uma Maternidade do município do Rio de Janeiro. Como recurso técnico-metodológico utilizou-se o discurso do sujeito coletivo (DSC). Após a análise dos discursos verificamos que para as gestantes a realização do teste significa a possibilidade de prevenir a transmissão vertical do HIV e como parte da assistência pré-natal. 0 pré-natal foi considerado pelas gestantes uma excelente oportunidade para a realização do teste anti HIV, para o conhecimento da condição sorológica e início precoce do tratamento. Conclui-se que o teste, para a maioria das gestantes, representa a possibilidade de proteger o filho do HIV, além de fazer parte da construção do papel materno a partir de um cuidado concreto com a saúde do bebê.

Palavras-chave: Cuidado Pré-Natal. Promoção em saúde. HIV

\begin{abstract}
The study had as objective, the knowledge and the analyzis of the meaning of the accomplishment for the test anti-HIV in the prenatal one for the pregnant women. One is about a research with qualitative approach and was carried through in a Hospital School and a Maternity at the city of Rio de Janeiro. As a resource of technician-methodological, the speech of the collective citizen was used (DSC). After the analysis of the speeches we verified that, for the pregnant women the accomplishment of the test means the possibility to prevent the vertical transmission of the HIV and as part of the prenatal assistance. The prenatal one was considered by the pregnant women an excellent chance for the accomplishment of the test anti HIV, for the knowledge of the serological condition and precocious beginning of the treatment. It is concluded that the test, for the majority of the pregnant women, represents the possibility to protect the son of the HIV, beyond being part of the construction of the maternal paper from a well-taken care of concrete with the health of the baby.
\end{abstract}

Keywords: Prenatal Care. Health promotion. HIV

\section{Resumen}

El estudio que tenía para que el objetivo sepa y analice el significado de la realización del anti-VIH de la prueba en el prenatal para las mujeres embarazadas. Uno está sobre una investigación con acercamiento cualitativo y fue ejecutado en una escuela del hospital y una maternidad de la ciudad de Rio de Janeiro. Como recurso técnico-metodológico el discurso del ciudadano colectivo fue utilizado (DSC). Después de que el análisis de los discursos, nosotros verificamos que para las mujeres embarazadas la realización de la prueba significa la posibilidad para prevenir la transmisión vertical del VIH y como parte de la ayuda prenatal. El prenatal era considerado por las mujeres embarazadas una ocasión excelente para la realización del anti VIH de la prueba, para el conocimiento de la condición sorological y del principio precoz del tratamiento. Se concluye que la prueba, para la mayoría de las mujeres embarazadas, representa la posibilidad para proteger al hijo del VIH, más allá de ser parte de la construcción del papel maternal de un cuidado bien-tomado del concreto con la salud del bebé.

Palabras-claves: Atención Prenatal. Promoción de la salud. HIV

1- Enfermeira graduada pela EEAN/UFRJ. Participante do Laboratório de Política, Planejamento e Assistência em DST/AIDS/HESFA/UFRJ. Endereço eletrônico: roberta_olives@yahoo.com.br. 2- Orientadora. Doutora em Saúde Coletiva pela Universidade do Estado do Rio de Janeiro (2003). Atualmente é Vice-diretora do Hospital Escola São Francisco de Assis/UFRJ. É Professora Adjunta da Escola de Enfermagem Anna Nery/UFRJ. Líder do grupo de pesquisas: Laboratório de Estudos em Política, Planejamento e Assistência em DST/AIDS (LEPPA DST/AIDS). 3- Co-orientadora. Enfermeira Supervisora do Hospital Maternidade Herculano Pinheiro - Rio de Janeiro. 


\section{CONSIDERAÇÕES INICIAIS}

Estudos epidemiológicos apontam para indicadores que delimitam o atual perfil da epidemia de AIDS, dentre eles destaco a feminilização. Esse processo envolve principalmente a faixa etária de 25 a 39 anos, denotando a associação com a via de contágio heterossexual e a relação com a idade reprodutiva da mulher ${ }^{1}$.

A vulnerabilidade das mulheres à AIDS está associada a uma lógica cultural da sexualidade, traduzida na submissão sexual das mulheres aos homens e na repressão sexual que permeia a educação das meninas, que, por sua vez, é constituída com base em mitos e preconceitos delimitados por gênero, sexo, opção sexual, classe e raça. Esses fatores interferem diretamente na prevenção e controle da epidemia, uma vez que dificultam a negociação do uso de preservativos e geram constrangimento na abordagem sobre sexo e saúde sexual'2.

Por essas razões, a realização do aconselhamento e da oferta do teste anti-HIV no pré-natal são de fundamental importância, pois asseguram à mulher o direito à informação e a receber tratamento e medicamentos antiretrovirais, evitando a transmissão vertical do HIV na maioria dos casos. Além disso, em cerca de $65 \%$ dos casos de gestantes HIV-positivas, a transmissão do vírus ocorre no período próximo ao parto ou durante o parto.

0 PN-DST/AIDS (Programa Nacional de DST/AIDS) recomenda a realização do teste anti-HIV com aconselhamento e com consentimento para todas as gestantes na primeira consulta pré-natal. Enfatiza-se a necessidade de realizar pelo menos uma sorologia durante o período gestacional.

Dessa forma, este estudo tem como objetivos: relacionar o significado para as gestantes da realização do teste anti-HIV durante o pré-natal e analisar os significados da realização do teste anti-HIV durante o pré-natal na perspectiva das gestantes.

Durante o levantamento bibliográfico sobre esta temática, verificou-se que existem poucas publicações científicas que abordam esta questão sobre a percepção da gestante diante da realização do teste anti-HIV, o que justifica a necessidade de novas pesquisas.

Considerando esse contexto, a pesquisa em tela visa contribuir para uma maior reflexão acerca dos aspectos que envolvem a testagem de gestantes no pré-natal, para que os profissionais compreendam melhor a visão da gestante. E, além disso, pretende colaborar para a produção de conhecimento na área de saúde da mulher e fortalecimento para a linha de pesquisa do LEPPA-DST/AIDS. ${ }^{1}$

\section{FUNDAMENTAÇÃO TEÓRICA}

\section{Diretrizes oficiais para a solicitação do teste anti-HIV no pré-natal}

Em 1984, 0 Ministério da Saúde elaborou o Programa de Assistência Integral à Saúde da Mulher (PAISM), marcando, sobretudo, uma ruptura conceitual com os princípios norteadores da política de saúde das mulheres e os critérios para eleição de prioridades neste campo. 0 PAISM teve como alguns de seus objetivos específicos a promoção da atenção obstétrica e neonatal, qualificada e humanizada, incluindo a ampliação e qualificação da atenção clínico-ginecológica, também para as portadoras da infecção pelo HIV e outras DST, e a promoção, conjuntamente com o PN-DST/AIDS, da prevenção e do controle das DST e da infecção pelo HIV/AIDS na população feminina ${ }^{3}$.

Considerando a existência de dilemas morais na ação de oferecimento do teste anti-HIV às gestantes durante o prénatal, serão discutidas aqui as formas de abordagem que atenderão aos direitos da mãe e do bebê, respeitando os princípios bioéticos de beneficência e autonomia.

A redução da transmissão vertical do HIV viabiliza-se quando é possível conhecer as gestantes soropositivas e fazer a profilaxia da transmissão, utilizando medicamentos antiretrovirais, principalmente a zidovudina - ou AZT. Isto impõe aos gestores de políticas públicas de saúde a obrigação de estabelecer estratégias eficazes para o rastreamento da infecção nas grávidas e, assim, proteger o futuro bebê quando a mãe está contaminada. Neste caso, proteger significa evitar a contaminação do feto, isto é, não prejudicá-lo. Alguns autores, no entanto, questionam se o "interesse presumível" do feto em um potencial tratamento teria prioridade sobre o interesse da mãe de não ser testada, se esta se recusasse a fazer o teste ${ }^{4}$.

Pela perspectiva dos direitos humanos, o teste compulsório constituiria uma violação do direito das mulheres sobre seus corpos e sua saúde. Além disso, também as políticas que estabelecem tratamentos compulsórios às gestantes soropositivas em benefício da saúde do feto seriam consideradas ameaça à integridade corporal das mulheres ${ }^{5}$.

0 Ministério da Saúde tem demonstrado, também, sua preocupação com a dimensão ética da oferta do teste anti-HIV, reconhecendo a necessidade de que esta ação aconteça de forma a garantir a cidadania e o respeito à pessoa humana $e$ destacando que os pilares éticos dos Centros de Testagem e Aconselhamento sejam constituídos pelos princípios de confiabilidade dos exames, agilidade no encaminhamento para os serviços de referência, gratuidade e confidencialidade, aliados às ações de aconselhamento ${ }^{6}$.

\section{$O$ aconselhamento em HIV/AIDS e a assistência pré- natal}

As informações sobre o significado e implicações do teste anti-HIV para o dia-a-dia são tão importantes quanto a realização deste. No caso da gestante, isso passa a ser ainda mais prioritário, pois a instabilidade emocional própria da gravidez fica exacerbada e pode trazer conseqüências desfavoráveis à mulher e ao concepto ${ }^{7}$.

Os momentos de atendimento à mulher representam espaços oportunos para a realização do aconselhamento e para o acompanhamento e apoio às medidas preventivas. Um desses espaços importantes é 0 atendimento pré-natal, considerando que geralmente este é o primeiro contato da mulher grávida

LEPPA DST/AIDS - Laboratório de Política, Planejamento e Assistência em DST/AIDS/HESFA/UFRJ 
com a atenção básica e que se deve estabelecer um vínculo entre a gestante e o profissional ${ }^{8}$.

0 aconselhamento persegue três objetivos essenciais: 0 primeiro, de investir na prevenção da doença, através de informar e abrir espaços para discutir a necessidade e as possibilidades de interferir no comportamento dos indivíduos, por exemplo, em relação ao uso de preservativos nas relações sexuais; o segundo, de garantir à clientela um espaço para estabelecer vínculos de confiança - seja com o profissional que a atende, seja com o serviço de saúde -, fundamental à discussão sobre prevenção e autocuidado e também para a eventualidade de comunicação de um resultado positivo do teste; e, o terceiro, de auxiliar na promoção dos direitos de cidadania ${ }^{4}$.

Segundo o Ministério da Saúde no manual de Recomendações para Profilaxia da Transmissão Vertical do HIV e Terapia Anti-Retroviral em Gestantes, o processo de aconselhamento poderá ser facilitado com a instituição de palestras e outros meios de informação para as gestantes e seus parceiros, na rotina dos serviços de pré-natal, otimizando o espaço entre a espera e a consulta. Essa prática informativa/ educativa fará da abordagem deste tema, para muitos ainda complicado, coisa natural e rotineira, evitando a banalidade da testagem anti-HIV. No pós-teste, o profissional deverá reforçar e discutir com a gestante o significado do resultado de seu teste, e, qualquer que seja o resultado, reforçar as informações sobre modo de transmissão do HIV e outras DST, e sobre as medidas de prevenção ${ }^{9}$.

\section{METODOLOGIA}

O estudo em questão foi desenvolvido segundo a abordagem qualitativa descritiva. 0 trabalho de campo foi realizado em um hospital escola e em uma maternidade ambos localizados no município do Rio de Janeiro. Nestas unidades todas as gestantes que comparecem à primeira consulta de pré-natal são aconselhadas a realizarem o teste anti-HIV.

Os sujeitos foram gestantes que realizam o pré-natal nessas unidades de outubro a novembro de 2007. A coleta de dados foi realizada após captação na sala de espera do pré-natal, identificando aquelas que já haviam aceitado realizar o teste anti-HIV.

A técnica para a coleta de dados foi uma entrevista semiestruturada, constituída por dois momentos: o primeiro, com dados que viabilizaram a caracterização das entrevistadas, e o segundo, com três questões abertas: "O que significa para você a realização do teste anti-HIV durante a gravidez?"; "Você acha que a realização do teste anti-HIV no pré-natal é importante? Por quê?"; e, ainda, "Que sugestões você daria para a oferta do teste anti-HIV no pré-natal?".

Foram realizadas 27 entrevistas, gravadas em meio magnético, sendo garantidos 0 anonimato e a confidencialidade das entrevistadas. 0 estudo foi submetido e aprovado pelo Comitê de Ética em Pesquisa (Protocolo n053/07). Os sujeitos da pesquisa assinaram o Termo de Consentimento Livre e Esclarecido, para participar do estudo, atendendo aos aspectos éticos da pesquisa, de acordo com a resolução 196/96 do Conselho Nacional de Saúde.

Os relatos, após transcrição, foram ordenados, classificados e analisados empregando-se a técnica do Discurso do Sujeito Coletivo (DSC), proposto por Lefèvre e Lefèvre ${ }^{10}$.

\section{RESULTADOS E DISCUSSÃO}

\section{Significado da realização do teste anti -HIV no pré-natal}

Os significados atribuídos à realização do teste anti-HIV tema central deste estudo - revelam que o teste, para a maioria das gestantes, é uma expressão de amor, cuidado e proteção para com seu filho que ainda vai nascer.

Quando questionadas sobre o significado do teste, grande parte das gestantes revela que, para elas, o teste representa a possibilidade de prevenirem a transmissão do HIV para seus filhos, caso estejam infectadas; ou seja, é a possibilidade de "salvar" a criança de uma doença que ainda traz em si muito estigma e preconceito da sociedade. A realização do teste, de certa forma, possibilita a tentativa de livrar os bebês de um sofrimento futuro, evitando assim, o sentimento de culpa. Como se pode observar no discurso a seguir:

Significa tranqüilidade, proteger meu filho de ficar doente, pois se der positivo, eu vou poder estar protegendo ele. Assim, eu posso saber se estou com o vírus ou não, para não passar para o bebê. Ah, eu sei os riscos que tem pro bebê, né, ele pode nascer com algumas seqüelas, mas só o estrago que ele (o HIV) faz na vida das pessoas é assustador. Eu irei salvar a criança para ela não ter, hoje em dia já tem essa possibilidade, não é? Já pode proteger o neném na gravidez, e, mesmo se pegar, tem tratamento. Logo, eu vou estar provando que amo meu filho e não quero que ele tenha essa doença. Seilá... de repente a criança nasce doente por causa de mim que não fui fazer o teste que é uma coisa tão simples, só tirar um pouquinho de sangue, né?! (DSC 01)

Neste discurso é possivel observar que as gestantes reconhecem a possibilidade de transmitir o HIV para seus filhos, caso estejam infectadas. Todavia também é notório 0 conhecimento das gestantes acerca da possibilidade de prevenção da transmissão vertical do HIV quando detectado antes do nascimento do bebê; isso é de extrema importância para a efetividade das ações de prevenção da transmissão vertical. Para que ocorra e se mantenha a diminuição do risco de infecção na criança, além de profissionais capacitados para acompanhamento da mãe e da criança, é necessário que haja a participação efetiva das mães em realizar todas as intervenções recomendadas. Entretanto, a mãe só vai aderir ao tratamento 
preventivo se estiver sensibilizada com a idéia de que a criança pode ser infectada e que, para evitar essa infecção, é necessário seguir todas as recomendações ${ }^{11}$.

Um outro aspecto relevante dentro desse significado está no papel materno construído socialmente no imaginário feminino, de que a mãe é responsável caso a criança apresente qualquer problema ao nascer. Em relação ao HIV, a mãe sentese culpada por ter falhado em seu papel materno, e, mesmo que não explicitamente, a sociedade a reprova por isso.

\section{0 teste anti-HIV como parte do cuidado pré-natal}

Um outro significado atribuído pelas gestantes ao teste anti-HIV foi o de ser parte do cuidado pré-natal. Para elas, o teste é uma expressão de cuidado, de amor, de responsabilidade e, além disso, de tranqüilidade, com a certeza de que não são responsáveis por transmitir nenhuma doença para seus filhos. Isso pode ser percebido no seguinte discurso:

Para mim significa um ato de amor e responsabilidade com o meu bebê, com a saúde dele, significa também tranqüilidade. 0 teste antiHIV é tão importante quanto os outros. Desde o momento que a gente aceita fazer o teste já está demonstrando carinho pelo seu filho, uma forma de amor pelo seu filho; você não quer que ele fique doente. Quem não quer fazer é porque não se preocupa com o feto, porque até então é um feto. $\dot{E}$ o cuidado com a criança desde o útero, é você querer o melhor para o seu filho e para você mesmo. Então significa não pensar mais só em mim, agora tenho que pensar por dois, porque se eu pensar só em mim como é que ele fica?Desta forma estou cuidando dele antes dele vir ao mundo, vou estar provando que amo meu filho e não quero que ele tenha essa doença. Eu posso ter, mais o meu bebê, não. (DSC 02)

A gravidez muitas vezes significa a possibilidade de resgate de sua identidade como mulher na sociedade. A gravidez não é unicamente um período caracterizado por um processo biológico natural, é uma representação ideológica que proporciona uma imagem plena da mulher-mãe ${ }^{12}$.

No século XIX, a maternidade passou a ser encarada como um sacerdócio, exigindo da mulher paciência e total dedicação 0 "instinto maternal" guia a mãe a uma dedicação e amor sem limites. À medida que a função materna abrangia novas responsabilidades, repetia-se cada vez mais alto que 0 devotamento era parte integral da "natureza" feminina, e que nele estava a fonte mais segura de sua felicidade ${ }^{13}$.

Dessa forma, as mães desejam cumprir seu "papel" da forma como a sociedade espera que seja, o de mãe protetora, provedora de alimento, cuidadora. Enfim elas consideram que cuidar da saúde do bebê é uma responsabilidade inserida em seu cotidiano.
Algumas gestantes consideram que a realização do teste anti-HIV no pré-natal significa a possibilidade de conhecerem sua condição sorológica e/ou evitar que sua doença se agrave, caso o resultado seja positivo. Elas não relataram nada relacionado a seus bebês. Como podemos afirmar no seguinte discurso:

É muito importante pra gente saber se tem ou não tem, vou estar tirando uma dúvida minha, porque tem muita doença; assim, evita que se agrave também. Porque a gente nunca sabe. Ainda mais os homens que não se tratam direito; mulheres vão sempre ao ginecologista então têm a oportunidade de saber se têm algum problema, agora os homens não...Para mim, é uma segurança ter certeza que não tenho, significa que estou bem de saúde. (DSC 03 )

Isso pode estar relacionado ao fato de muitas gravidezes não terem sido desejadas, o que dificulta a conscientização do papel materno e faz com que elas não citem preocupações com seus bebês neste momento. A construção do papel materno para algumas mulheres pode ocorrer apenas após o parto, quando podem ter um contato mais "concreto" com seus filhos. Os sinais de amor materno surgem na ocasião dos primeiros movimentos fetais, e, se isso não ocorrer, poderão ser propiciados através dos contatos físicos após o parto ${ }^{14}$.

\section{A importância da realização do teste anti-HIV no pré-natal}

Quando as gestantes foram questionadas se consideravam importante a realização do teste anti-HIV no pré-natal, todas responderam que sim, que este é um momento de extrema importância para a realização do teste.

Foi possível observar pelos discursos que as gestantes consideram a realização do teste no pré-natal de extrema importância para o início do tratamento; isso nos remete ao conhecimento adquirido por elas através das falas dos profissionais de saúde, durante a oferta do teste. Um exemplo disso está no discurso a seguir:

É muito importante porque, se eu tiver, eu já vou procurando tratar, né? Ou seja, é importante para que não passe para ele, para que eu tome os remédios e meu filho não seja infectado; e também porque pode passar para a criança pela amamentação, então a mãe já sabendo o risco... Com isso, dá pra saber se o feto vai ter uma chance de um tratamento mais rápido, e agora eu sei que se eu estiver contaminada posso estar cuidando dessa contaminação e o bebê vai nascer saudável. (DSC 04) 
De acordo com o Ministério da saúde, ${ }^{9}$ a taxa de transmissão vertical do HIV, sem qualquer intervenção situa-se em torno de $25 \%$. No entanto, diversos estudos publicados na literatura médica demonstram a redução da transmissão vertical do HIV para níveis entre $0 \%$ e $2 \%$, por meio de intervenções preventivas, tais como: o uso de anti-retrovirais combinados, o parto por cesariana eletiva, o uso de quimioprofilaxia com AZT na parturiente e no recém-nascido, e a não-amamentação. A redução da transmissão vertical com o uso de zidovudina é independente do nível de carga viral; estudos mostraram a redução mesmo quando a carga viral era menor que 1.000 cópias/ml. Está amplamente comprovado que o uso de terapia anti-retroviral combinada é capaz de reduzir significativamente a carga viral plasmática do HIV para níveis indetectáveis.

Diante disso, cabe destacar a importância da educação em saúde para a população. À medida que a população adquire conhecimentos, ela pode fazer escolhas conscientes que serão determinantes para a sua saúde e, neste caso, para a saúde das crianças que irão nascer.

As gestantes consideram que o pré-natal é a oportunidade para realizarem o teste, ou porque nunca lhes foi ofertado ou porque tinham vergonha de solicitá-lo e, além disso, é um excelente momento para tirarem suas dúvidas. Como se pode observar no discurso a seguir:

Acho que é importante porque é uma maneira de saber como eu estou, se tenho algum problema. Assim, eu posso ficar sabendo se estou com AIDS ou não e se meu bebê vai se prejudicar. É muito importante porque às vezes a mulher sai com o cara, aí não sabe... a gente sabe da nossa vida, agora da dele não... a gente fica com medo não é? A pessoa vai, confia, tem muitas mulheres que ficam 3 meses com o cara, aí transam sem camisinha, não sabem quem ele namorou lá na frente, aí passa tudo, não só a AIDS, a sífilis e outras coisas também...De qualquer forma, seja marido ou namorado, a gente está se arriscando; então eu acho uma boa oportunidade, é só dizer sim ou não se quer fazer, é prático...eu concordei. (DSC 05)

As questões relacionadas ao HIV/AIDS infelizmente trazem em si as marcas do preconceito e da discriminação. Muitas pessoas até hoje sentem vergonha em procurar os serviços de saúde para realizarem o teste, embora tenham dúvidas sobre sua sorologia. Diante disso, é nítida a importância de campanhas de conscientização da população sobre a importância da realização do teste em qualquer momento de suas vidas em que se sentirem expostas a situações de risco, como sexo sem preservativo ou uso de drogas injetáveis.

A proporção de mulheres que souberam estar infectadas pelo HIV antes da gravidez ainda é muito pequena. Isto sugere a necessidade do oferecimento mais amplo do teste entre a população feminina em geral, mediante 0 aconselhamento, principalmente antes de engravidar ou planejar a gravidez ${ }^{15}$.

\section{Sugestões das gestantes para a oferta do teste anti-HIV no pré-natal}

Quando as gestantes foram questionadas sobre a oferta do teste, algumas sugeriram melhorias nas estratégias utilizadas, outras não deram nenhum tipo de sugestão, e outras ainda sugeriram que o teste fosse compulsório.

A maioria das gestantes considerou as informações recebidas acerca do teste adequadas e revelaram estarem satisfeitas com 0 atendimento recebido no serviço, como podemos observar no seguinte discurso:
Bom, quando eu fiz os exames de HIV eu assisti à palestra para gestantes, foi tudo direitinho. Da forma que foi eu considero ideal, está ótimo. Eles pedem para a gente fazer, e a gente vai fazer $e$ assiste à palestra. A palestra é maravilhosa, elas explicam muito bem. Aliás, eu sempre tive muita informação aqui no pré-natal. Por isso não tenho sugestões, do jeito que está está muito bom, muito claro. (DSC 06)

Tanto no momento da oferta, que ocorreu na primeira consulta de pré-natal com todas as entrevistadas, quando na ida ao CTA, através do aconselhamento coletivo, as gestantes associaram a clareza das informações transmitidas com a qualidade do atendimento. De acordo com o Ministério da saúde ${ }^{9}$, a qualidade do intercâmbio a que se propõe 0 aconselhamento permitirá ao profissional de saúde estimar a possibilidade de haver (ou ter havido) para a mulher, ou seu parceiro, situações de exposição ao risco de infecção pelo HIV e outras DST, no presente ou em épocas passadas. Para a mulher, a qualidade desse intercâmbio significará uma oportunidade para avaliar a exposição ao risco de infecção pelo HIV, preparando-a para a recepção do diagnóstico de HIV ou para a adoção das medidas de prevenção desta infecção e de outras DST.

Destacamos que houve gestantes que relataram que não receberam informações satisfatórias sobre o teste, que ficaram com dúvidas e até receberam informações "erradas". Como ilustra o discurso a seguir:

Eu acho que deveria ser mais explicado porque para mim não ficou muito claro... no dia do teste não falaram que o bebê podia nascer sem; no caso, o que me explicaram é que, a mãe tendo, o bebê também fica com AIDS. Poderia ser explicado melhor. Eu acho que deveria falar o que acontece com o feto, como é a doença; tem muita gente que não sabe como é a doença, se é grave, tanto é que não explicaram para mim... como é, quais os sintomas, não explicaram nada. Deveria ser tipo 
uma conversa. Acho também que o teste deveria vir mais rápido, porque eu vim na primeira consulta, na segunda, e só na terceira que eles me entregaram o resultado; demorou um pouco, se fosse mais rápido seria melhor. (DSC 07)

Pode-se relacionar esta questão tanto com a própria dificuldade de assimilação das informações pelas gestantes quando com a falta de profissionais capacitados para realizar um aconselhamento individual e coletivo que atenda às necessidades da clientela.

Para que, de fato, o aconselhamento seja efetivo, é necessário que o cliente se aproprie de informações geradas pela ciência e as transforme em um instrumento principal na adoção de comportamentos com menor risco de transmissão das DST/AIDS ${ }^{16}$.

Ainda existem muitos obstáculos nos serviços de saúde para a implantação do aconselhamento, principalmente em relação aos profissionais. Destacam-se, ainda, as dificuldades apontadas pelos aconselhadores, como a falta de tempo disponível para a quantidade de conteúdo, o receio de não passar informações que eles julgam indispensáveis ao cliente e a baixa valorização da atividade. Além disso, o SUS estabelece uma relação paradoxal com o aconselhamento. A integralidade, um dos marcos desse sistema, também permeia 0 aconselhamento; entretanto, a falta de adequação da capacidade instalada dos serviços de saúde e a deficiência no número de aconselhadores provocam a massificação dos serviços e imprimem na equipe de aconselhamento, além de impaciência, a insatisfação no cliente $^{16}$.

As gestantes consideram o teste tão importante que chegam a relatar que este deveria ser obrigatório, como podemos observar no seguinte discurso:

Acho também que o teste deveria ser obrigatório, porque é uma coisa que não deve faltar até por causa do neném, porque pode evitar que ele nasça doente. Acho que não deveria ser oferecido; todos teriam e devem fazer, mesmo as mães que não queiram, deveria ser obrigatório. Aliás, deveria ser normal como qualquer outro exame, na verdade deveria ser oferecido até antes da gravidez, na consulta de ginecologia, porque é a saúde da criança. A mãe que não quer saber se tem HIV é ignorante. (DSC 08)

0 teste anti-HIV não pode ser compulsório, pois isso infringe os aspectos éticos e legais e sempre deve ser oferecido através do aconselhamento pré-teste, sendo também garantido 0 aconselhamento pós-teste. 0 aconselhamento em DST/AIDS não objetiva apenas a transmissão de informações, mas principalmente a construção de um plano de redução de risco à transmissão das DST/AIDS. 0 interesse não é apenas o conhecimento do status sorológico, mas sim a avaliação de risco diante da problemática do HIV e a adesão às medidas de prevenção da transmissão vertical, especificamente durante a gestação. É um trabalho de educação em saúde.

\section{CONSIDERAÇÕES FINAIS}

A construção deste estudo tornou possível a observação de que a realização do teste anti-HIV no pré-natal envolve aspectos subjetivos de importante valor para as gestantes e que é imprescindível considerar esses aspectos na prática profissional, para uma contribuição real e uma assistência mais humanizada que atenda, de fato, às necessidades da população. Possibilitou ainda uma reflexão acerca dos aspectos que envolvem a realização do teste anti-HIV no pré-natal sob a visão das gestantes, oferecendo mais uma fonte de informação, para propiciar modificações nas ações dos profissionais de saúde que trabalham com gestantes nos serviços de pré-natal.

Foi possível relacionar que, para as gestantes, a realização do teste neste momento representa a possibilidade de prevenirem a transmissão do HIV para seus bebês, assim como uma qualificação da atenção pré-natal. Relacionam a sua responsabilidade como mães e sentem-se no dever de proteger, cuidar e pensar no futuro da criança. Isso é percebido através das falas e nas expressões faciais de satisfação, e nos momentos de silêncio em que procuravam palavras para expressar o que significava a realização deste teste neste momento tão peculiar de suas vidas.

Além disso, também foi citado o fato de que algumas mães ainda não pensavam em seus bebês, e que o teste, para elas, era a possibilidade de conhecerem a sua condição sorológica e iniciar precocemente o tratamento antes do aparecimento de doenças oportunistas. Em relação ao momento da realização do teste, todas elas consideraram importante a realização no pré-natal, seja pelo fato de poderem iniciar o tratamento 0 mais rápido possível para tentarem reduzir os danos a elas e a seus bebês ou apenas como uma oportunidade para realizarem o teste sem se sentirem constrangidas na realização do exame. Além disso, podemos observar nos discursos das gestantes que existe uma deficiência na oferta do teste anti-HIV entre a população feminina fora da gestação, pois a maioria só conhece a oferta da sorologia durante o pré-natal.

No que diz respeito às sugestões para a oferta do teste, algumas gestantes demonstraram-se satisfeitas com a forma pela qual Ihes foi oferecido o teste; outras, por sua vez, reclamaram da demora do resultado e das informações fornecidas que não foram claras.

Diante dos resultados encontrados, cabe destacar que ainda há um longo caminho a ser percorrido no sentido de qualificar a atenção pré-natal. Sem dúvidas fica evidente a necessidade de sensibilizar, mobilizar e capacitar os profissionais envolvidos com a assistência pré-natal. É fundamental que as gestantes 
sintam-se acolhidas nos serviços de pré-natal e tenham conhecimento para tomar suas decisões conscientes e com responsabilidade. Somente com esta qualificação será possível

\section{Referências}

1- Sampaio Neto LFS, Silva SC, Condi GG, Pinto PC, Novo NF. 0 impacto do conhecimento prévio da soropositividade em parturientes. DST - J Bras Doenças Sex Transm 2003 abr/maio/jun; 4(2): 61-66.

2-Souza SMB, Andrade J. A soro prevalência para HIV em gestantes acompanhadas pelo Programa de Saúde da Família de Campina Grande, Paraíba (PB). Rev Baiana Saude Publica 2003 jan/jul; 27(1/2): 28-37.

3-Ministério da Saúde (BR). Política Nacional de Atenção Integral à Saúde da Mulher: princípios e diretrizes. $1^{\text {a }}$ ed. Brasília (DF); 2004.

4- Israel GR. Como é que eu vou dizer para a gestante? Dilemas morais da oferta do teste anti-HIV a gestantes em trabalho de parto: uma contribuição da biolítica. [dissertação de mestrado] Rio de Janeiro (RJ): Escola Nacional de Saúde Pública/FIOCRUZ; 2002.

5-Schüklenk UDO. Aids: individual and 'public' interests. In. Kuhse H, Singer P. A companion to bioethics. Oxford (USA): Blackwell Publishers; 1998. p. 343-53.

6- Ministério da Saúde (BR). Manual de Controle das Doenças Sexualmente Transmissíveis. 4ª ed. Brasília (DF); 2006.

7-Araújo CLF. A solicitação do teste anti-HIV no pré-natal em Unidades Básicas de Saúde do Município do Rio de Janeiro: políticas e realidades. [dissertação de mestrado]. Rio de Janeiro (RJ): Universidade do Estado do Rio de Janeiro; 1997.

8- Ministério da Saúde (BR). Aconselhamento pré e pós-teste anti-HIV como estratégia de melhoria da cobertura de testagem em gestantes e prevenção da transmissão vertical do HIV. Brasília (DF); 2006. a efetiva redução das taxas de transmissão vertical do HIV, potencializando as ações de prevenção das DST/HIV entre as mulheres.
9- Ministério da Saúde (BR). Recomendações para profilaxia da transmissão vertical do HIV e terapia anti-retroviral em gestantes. Brasília (DF); 2007.

10- Lefévre F, Lefévre AMC. 0 discurso do sujeito coletivo: um novo enfoque em pesquisa qualitativa e desdobramentos. $2^{\mathrm{a}}$ ed. Caxias do Sul (RS): Educs; 2005.

11- Neves LAS, Gir E. Crenças das mães soropositivas ao HIV acerca da transmissão vertical da doença. Rev Latino-am Enfermagem [on- line] 2006 set/out. [citado 14 ago 2008] 14(5): [aprox 10 telas]. Disponível em: http: //www.scielo.br.

12- Ruggiero EMS. Gestante portadora do vírus HIV: vida e significado. [tese de doutorado]. Ribeirão Preto (SP): Escola de Enfermagem de Ribeirão Preto/USP; 2000.

13- Badinter E. Um amor conquistado: o mito do amor materno. São Paulo (SP): Hucitec. 1986.

14- Pinheiro MTS. Reflexões sobre as bases do amor materno. In: Hilferding M, organizadora. As bases do amor materno. São Paulo (SP): Escuta; 1991. p.133.

15-Cavalcante MS, Ramos Junior AN, Silva TMJ, Pontes LRSK. Transmissão vertical do HIV em Fortaleza: revelando a situação epidemiológica em uma capital do nordeste. Rev Bras Ginecol Obstet [on- line] 2004 [citado set 2007]; 26(2): [aprox. 8 telas]. Disponível em: http://www.scielo.br.

16-Araújo CLF, Camargo Junior KR. Aconselhamento em DST/HIV: repensando conceitos e prática. Rio de Janeiro (RJ): Folha Carioca; 2004 